\title{
PEER FEEDBACK OVER TIME
}

\author{
Julia N. Smith and Thomas A. O'Neill \\ University of Calgary \\ julia.smith@ucalgary.ca
}

\begin{abstract}
Given the ubiquity of teamwork in engineering education and industry ${ }^{I}$, developing teamwork skills in undergraduate students is a critical component of their training. This is supported by the inclusion of 'individual and teamwork' as a graduate attribute by the Canadian Engineering Accreditation Board ${ }^{2}$. The current work explores the development of teamwork skills through the use of multiple administrations of peer feedback, in order to explore the value of using several administrations and support past findings that have suggested increased administrations provide incremental improvements.

Additionally, the paper discusses the use of an empirically validated and user-friendly tool used to deliver the peer feedback assessments. The results suggest that students find the tool easy to use and that they believed the feedback they received and gave was accurate and useful. Together, these results suggest that peer feedback, delivered using the ITPMetrics.com platform, is an effective and well-received method of fostering soft-skill development in engineering students.
\end{abstract}

Keywords: teamwork; peer feedback; graduate attribute

\section{INTRODUCTION}

Strong teamwork skills have been identified by both the Canadian Engineering Accreditation board (CEEA) and by industry ${ }^{1}$ as critical for success as an engineer. Fostering teamwork skills in undergraduate students is therefore a key priority for engineering undergraduate programs, but this can present a challenge as the process involves soft skills rather than technical capabilities. The current study contributes to this field by exploring the impact of peer feedback and how students respond to receiving and providing peer feedback.

Peer feedback is a pedagogical technique in which participants assess themselves and their teammates on a given set of attributes. The basis of peer feedback is that by being introduced to the fundamental teamwork competencies, maintaining awareness of one's own and others' teamwork competencies, and providing and receiving feedback on those competencies, participants will be able to monitor and adapt their behaviour to become stronger team members ${ }^{3}$. This has been supported by past research, which has established peer feedback as a useful means of improving the behaviors that are the focus of the peer feedback ${ }^{3,4,5}$. Furthermore, teammates can provide unique insight into one another's behaviours, as they typically interact more closely with one another than with their instructors or teaching assistants ${ }^{3}$.

Peer feedback is frequently conceptualized in teamwork research using the competencies developed by Ohland et al. ${ }^{6}$. The psychology team at the University of Calgary has adapted these competencies to consist of the following: communicating with team members, having a strong foundation of knowledge, skills and abilities, commitment to the team's work, emphasizing high standards, and keeping the team on track.

Past research suggests that the quality of ratings of teamwork competencies improve after students participate in multiple rounds of peer feedback ${ }^{7}$. This may be because students feel more comfortable using the tool as they grow accustomed to the process- past research has also found that students' comfort in providing their teammates with feedback increases over the course of multiple administrations ${ }^{7,8,9}$. Furthermore, students may theoretically gain a better grasp on the required skills and behaviours for being an effective team member over time, suggesting that they may be better able to provide accurate ratings with increased teamwork experience ${ }^{7}$.

A concern with the use of peer feedback is students' tendency to give more positive ratings than deserved to their peers, a phenomenon called "evaluation inflation"10. This has previously been identified as problematic for peer feedback's validity ${ }^{11}$. To target this type of feedback inflation, past research suggests ensuring that students have a strong understanding of the assessment procedure $^{12}$. Providing students with clear instructions and emphasizing the importance of peer feedback has been linked to peer feedback that more closely relates to the more objective feedback from instructors ${ }^{12}$. This points to both the value of using repeated administrations, to increase students' understanding through hands-on involvement, and of implementing a user-friendly tool to administer the feedback, to ensure that the process goes smoothly for students. 
Gathering data on students' perceptions of the tool, namely its ease of use and usefulness, is also critical for ensuring that students are engaged with the system. Past research on e-learning has found that perceived usefulness and ease of use predict user satisfaction ${ }^{13,14}$ which has in turn been identified as mediating the relationship between the predictors and the user's tendency to continue using the system ${ }^{13}$. Taken together, this suggests that gathering data on students' perceptions of the tool is critical to approximate student satisfaction with their peer feedback experience.

Therefore, the current study sought to replicate and expand upon past findings and to further explore students' reactions to the tool.

\section{METHOD}

\subsection{Participants}

The sample was composed of undergraduate students in the Schulich School of Engineering at the University of Calgary, representing fourth-year students from a variety of disciplines. The sample includes: a fourth-year electrical engineering course $(N=161)$, a multidisciplinary fourth-year capstone course $(N=35)$, a fourth-year mechanical engineering course $(N=147)$ and a fourth-year geomatics course $(N=27)$, for a total sample size of 370 participants. Of the 196 students who were asked to indicate their gender, 38 identified as female and 158 identified as male (gender information was not gathered for the fourth-year mechanical engineering course or the fourth-year geomatics course).

In each course sampled, students worked in teams on a series of projects, with a portion of their course mark dependent on the work they produced as a team. Students typically receive a small amount of course credit for participating in the assessment (e.g. .5\%) to encourage completion.

\subsection{Materials and Procedure}

The fourth-year capstone, electrical engineering, and mechanical engineering courses were full-year courses and students participated in two peer feedback assessments per semester. For the capstone and electrical engineering courses, the assessments occurred in Week 5 and Week 13 of the fall semester, and Week 2 and Week 8 of the winter semester. For the mechanical engineering course, the assessments occurred during Week 10 and Week 13 of the fall semester, and Week 4 and Week 13 of the winter semester. The geomatics course sampled was also a full-year course, and students participated in one peer feedback assessment in the fall semester (Week 10) and two in the winter semester (Week 6 and Week 14, after the classes had ended). Students were asked to participate in peer feedback assessments after having had the opportunity to form interpersonal relationships and become familiar with one another to provide more accurate ratings.

As part of their course requirements, students were asked to participate in the peer feedback assessments on ITPMetrics.com, a free online platform that includes the peer feedback assessments amongst a suite of other assessments designed to improve self-awareness and individual and team performance. Prior to completing the assessments, a representative from the ITPMetrics team visited each classroom to provide information on the assessment and how to give effective written feedback (i.e., writing feedback that is specific, behavioural, and future-oriented). Students are then emailed a link to complete the assessments online, and asked to indicate the extent: the instruction asks students to 'Please rate the extent to which this person engages in this behaviour) on a Likert-type scale of 1-5, where $1=$ Strongly Disagree and 5 = Strongly Agree) in the items associated with each of the five aforementioned competencies. Students are also asked to provide written feedback for their teammates. This system differs from the anchors used by the CATME system, which provides users with a description of the behaviours associated with each level of competency and asks users to select the appropriate level; this change in the interface was done to enhance the user's experience with the platform.

Additionally, students were asked to indicate their perceptions of the tool. Students in the fourth-year electrical engineering course and the fourth-year capstone course were asked to respond on a 5-point Likert type scale to an eleven-item scale on the tool's ease of use and aesthetic appeal, where $1=$ Unsatisfactory and $5=$ Outstanding; a sample item is "It was easy to understand the format of the tool". Students were also asked to respond to a ten-item scale on their perceptions of the feedback itself, i.e. on its utility and the accuracy of the feedback they gave and receive; a sample item is "My team members will provide reliable feedback regarding my performance in the team". Students in the fourth year mechanical engineering course responded to six-item truncated version of the scale on their perceptions of the feedback's utility and students in the fourth-year geomatics course responded to a five-item version of the utility scale

The ITPMetrics platform then generates a customized report for each student (please see Appendix A for a sample report). This report provides information on the average score on each competency given to each student by their peers, their self-reported score, and their 
competency level based on the score they received from their peers. All feedback is rendered anonymous such that students' confidentiality is protected. By comparing students' self-rating and their peer rating, students can identify blind spots that could be development areas or unacknowledged strengths, depending on if the self rating is higher or lower than the peer rating. The report also provides suggested improvement behaviours for each teamwork competency.

Following the peer feedback assessment, members of the ITPMetrics team then debrief the assessments with the students and encourage students to discuss their assessments with their team members and to set goals to improve their competencies. In the event that there is not a scheduled debrief session, the reports also include suggestions on how to reflect upon their results and foster an open conversation with team members.

\section{RESULTS}

\subsection{Peer feedback ratings}

Two ANOVAs were used to compare the students' peer-rated scores on each competency over time and to compare the different classes to one another. The first, a mixed-model ANOVA, compared the three courses that had had four peer feedback administrations to one another and to see changes over time. Sphericity was not assumed, Mauchly's $W=.649, p<.001$, therefore the GreenhouseGeisser corrected values are reported. There was a significant positive effect of time, $F(2.30,781.33)=5.85$, $p=.002$, such that there was a net positive improvement of peer-rated overall teamwork competency over time. There was a significant quadratic trend, $p<.001$, such that the average increased significantly from the first administration $(M=4.55, S D=.39)$ to the second $(M=$ $4.62, S D=.39)$, to the third $(M=4.64, S D=.41)$; the fourth administration was slightly lower, $M=4.60, S D=$ .58 .

The interaction between the class students were in and their peer-rated competency rating was not significant, $F(4.60,781.33)=.718, p=.599$, suggesting that the effect of repeated peer feedback administrations did not differ based on the class students were in. There was a significant main effect of class, $F(2,340)=7.97, p<$ .001 , suggesting that students' peer feedback ratings differed depending on which class they were in. The fourth-year electrical engineering and capstone courses did not significantly differ from one another, $p=1.00$, nor did the fourth-year capstone course and the mechanical engineering course, $p=.414$. The mechanical engineering course differed significantly from the electrical engineering course, $p<.001$. Please see Fig. 1 for a visual depiction of the data.
The second within-subjects ANOVA analyzed the geomatics course that had had three peer feedback administrations. Sphericity was not assumed, Mauchly's $W=.018$, therefore the Greenhouse-Geisser corrected values are reported. There was a significant effect of time, $F(1.57,40.82)=13.85, p<.001$, such that the average overall peer-rated competency score significantly improved with each administration. The second administration $(M=4.15, S D=.083)$ had a significantly higher average competency rating than the first $(M=3.95$, $S D=.099)$, and the third administration had significantly higher competency ratings than did the second, $M=4.46$, $S D=.12$. The data displayed a significant linear trend over time, $p<.001$. Please see Fig. 2 for a visual depiction of the data.

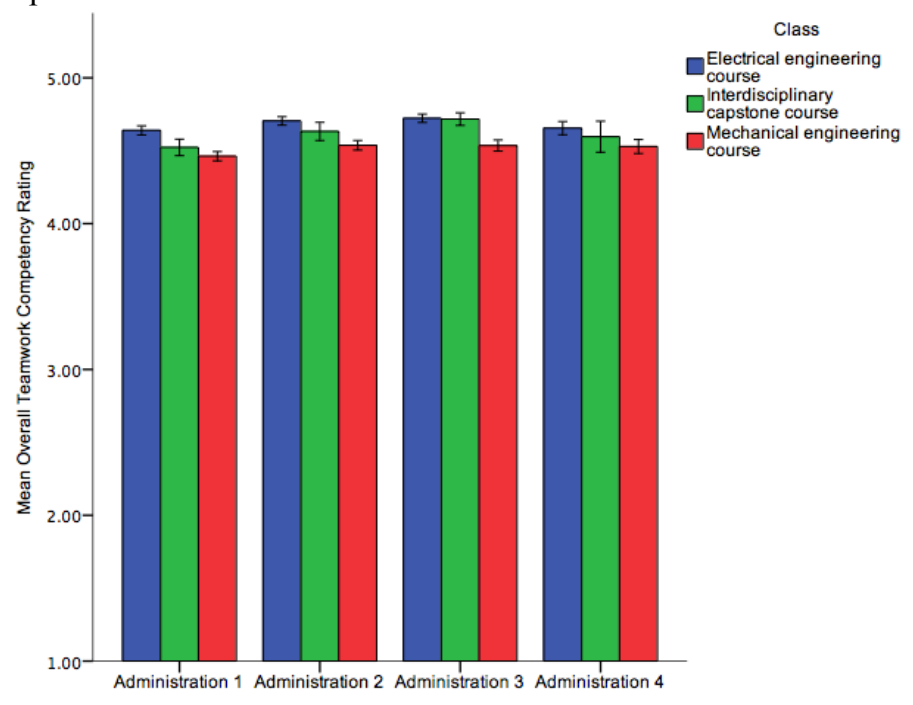

Fig 1. Students' peer-rated competency ratings over time. Error bars represent standard error of the mean.

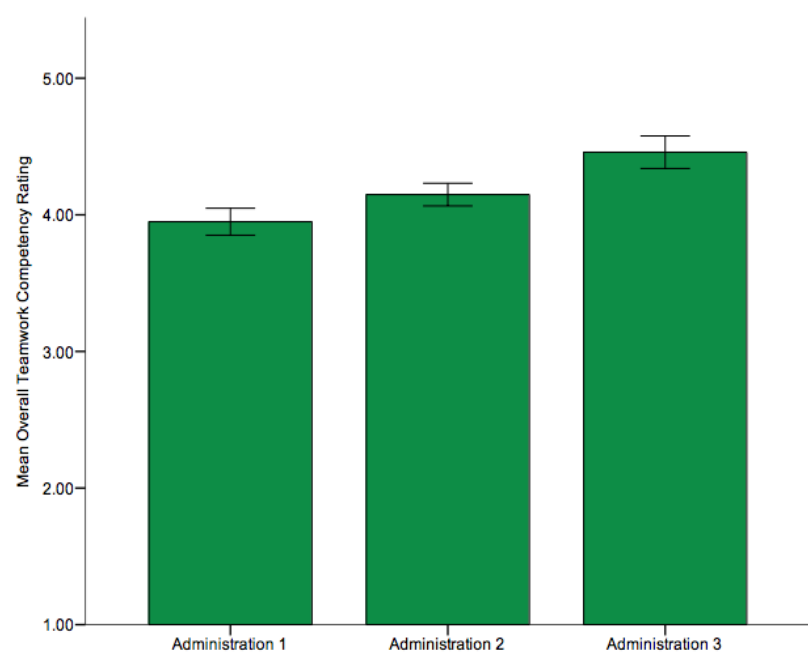

Fig 2. Students' peer-rated competencies over time in a geomatics course. Error bars represent standard error of the mean. 


\subsection{Student reactions}

Descriptive statistics were calculated to assess students' perceptions of the tool's utility and ease of use (gathered at the first peer feedback administration). Analyses were conducted based on the students' first administration to gather their perceptions based on their initial exposure to the tool in their course.

The students in the electrical engineering and capstone courses demonstrated positive reactions to the tool's ease of use, $M=4.43, S D=.57$. Please see Fig. 3 for a visual depiction of the responses. These students also demonstrated positive reactions to the tool's accuracy and utlity, $M=4.04, S D=.54$. Please see Fig. 4 for a visual depiction of the responses.

Students in the mechanical engineering course indicated that they believed the accuracy of the feedback received and provided was high, $M=4.44, S D=.68$. Students in the fourth-year geomatics course also indicated that they believed the tool was highly useful, $M$ $=4.08, S D=.81$.

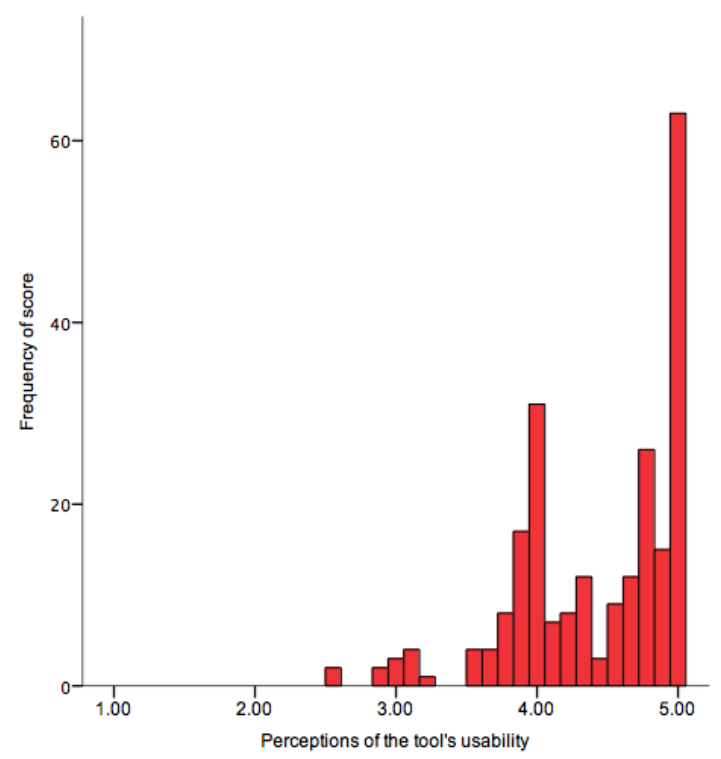

Fig 3. Students' perceptions of the tool's ease-of-use, where the $y$-axis represents the frequency of that average score in the sample.

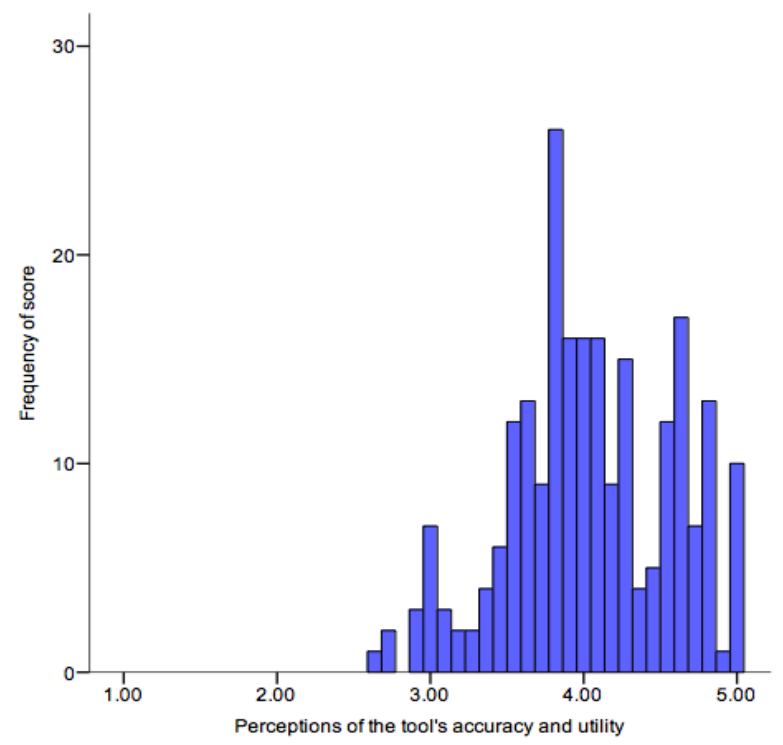

Fig 4. Students' average rating of their perceptions of the tool's accuracy and utility, where the $y$-axis represents the frequency of that average score in the sample. 


\section{DISCUSSION}

Based on the study's findings, students seem receptive to using an online platform to administer and receive peer feedback, and appear to improve their teamwork skills over the course of multiple administrations. While these results are promising for assisting engineering educators in fostering teamwork skills, alternative explanations and the study's limitations should nonetheless be considered to further explore the impact of peer feedback and conditions under which its effectiveness is optimized. The quadratic trend seen in the classes that participated in four peer feedback administrations suggests that the while the peer feedback supports development of improved teamwork skills, more research is required into the conditions surrounding peer feedback administration and to explore the optimal amount of peer feedback administrations.

There are several possible explanations for the trend seen in this data. One potential reason for the quadratic pattern could be that students' understanding of effective team member behaviour increases over time, resulting in harsher, but potentially more accurate, ratings. This theory is supported by past research, which has found that both students' understanding of teamwork skills and confidence in the accuracy of their feedback increases with more experience in providing this type of evaluation ${ }^{7}$. Future research could explore this further by matching students' feedback with that from teaching assistants and instructors, as done in past research (Choi et al) and with data such as project grades and individual course grades. As past research matching peer feedback and instructor ratings conducted by asking students to provide feedback on one another's writing and assignments $^{12}$, it would be useful to extend this to a context where feedback is given to one's peers on their teamwork behaviour and matched with instructor or teaching assistant perceptions and/or student team and individual grades.

Another possible reason for this trend lies in contextual factors surrounding the peer feedback assessments. Factors including, but not limited to, upcoming midterms, presentations, and recently receiving a project-based grade or feedback could impact students' perceptions of their teammates. This could be contributing to the differences between the classes who participated in four assessments explored in this paper. One instructor taught two of the courses and the feedback was spaced at the same intervals, whereas the other course was taught by another individual and did not have the same intervals between feedback rounds. The current study is limited in that data on other contextual factors was not collected. In future, instructors and researchers should thus be cautioned to consider other factors that could impact students' ratings and to gather that data in order to control for their possible impact.

Students' positive perceptions of the tool also indicate that peer feedback, as delivered by an online platform, is a useful, easily applied method of developing student teamwork skills. Students on average rated the tool as both very easy to use and very useful and accurate. Furthermore, the dispersion of their overall ratings seen in Fig. 3 and Fig. 4 displays that scores are clustered toward the high end of the response scale, suggesting that the students surveyed found the tool at least somewhat straightforward and that the process was, at minimum, moderately useful to them. This suggests that students byand-large respond positively to the use of this tool, which has positive implications for both student satisfaction and engagement with the tool and for the accuracy of their feedback. Past research has found that perceived usefulness and usability impact user satisfaction ${ }^{13,14}$ and that a clear understanding of the assessment process leads to more valid ratings ${ }^{12}$. Furthermore, perceptions of usefulness and satisfaction with an e-learning system have been linked to student intentions to continue using the system (Lin and Wang, 2012): this suggests that using the ITPMetrics tool could promote student participation in the peer feedback process.

Given that students rated the tool as simple to use and useful upon their first exposure to it and displayed improvements after participation in the peer feedback process, this suggests that the tool can be easily applied in engineering education classrooms and is a valuable technique for coaching a key graduate attribute.

\section{CONCLUSION}

Taken together, the results suggest peer feedback is an effective, user-friendly method of improving students' awareness of what being a good team member requires and their proficiency on those teamwork behaviours. Students displayed improvements over time with participation in peer feedback assessments and rated the tool as both user-friendly and of high utility to them. This supports the past research displaying the value of using peer feedback and highlights a tool that can be easily implemented to foster teamwork competency in engineering classrooms, thereby equipping students with the transferable skills they will require for success in their careers.

\section{ACKNOWLEDGEMENTS}

We would like to thank the Schulich School of Engineering at the University of Calgary for their ongoing support and continued collaboration. 


\section{References}

[1] L. J. Shuman, M. Besterfield-Sacre, and J. McGourty, "The ABET "Professional Skills"- Can they be taught? Can they be assessed?" Journal of Engineering Education, 94, 2005, pp. 41-55.

[2] Canadian Engineering Accreditation Board: 2016 Accreditation Criteria and Procedures. (n.d.). Retrieved from https://engineerscanada.ca/sites/default/files/ Accreditation-Criteria-Procedures-2016final.pdf

[3] S. Brutus and M. B. L. Donia, "Improving the effectiveness of students in groups with a centralized peer evaluation system." Academy of Management Learning \& Education, 9, 2010, pp. 652-662.

[4] M. Donia, T. A. O’Neill, and S. Brutus, "Peer feedback increases team member performance, confidence, and work outcomes: A longitudinal study." Academy of Management Learning and Education, under review.

[5] P. G. Doinick, R. R. Reilly and J. W. McGourty, "The effects of peer feedback on team member behavior." Group and Organization Management, 22(4), 1997, pp. 508-520.

[6] M. Ohland, M. L. Loughry, D. J. Woehr, L. G. Bullard, R. M. Felder, C. J. Finelli,....D. G. Schmucker, "The comprehensive assessment of team member effectiveness: Development of a behaviorally anchored rating scale for self and peer evaluation." Academy of Management, 11, 2012, pp. 609630.
[7] S. Brutus, M. B. L. Donia, and S. Ronent, "Can business students learn to evaluate better? Evidence from repeated exposure to a peer-evaluation System" Academy of Management Learning and Education, 12, 2013, 18-31.

[8] W. Cheng and M. Warren, "Hong Kong students' attitudes toward peer assessment in English language courses", Asian Journal of English Edition Language Teaching, vol. 6, 1996, 61-75.

[9] W. Cheng and M. Warren, M. "Having second thoughts: Student perceptions before and after a peer assessment exercise." Studies in Higher Education, vol. 22, 1997 233-240.

[10] A. Tziner, K. R. Murphy, and J. N. Cleveland, “ Contextual and rater factors affecting rating behavior." Group and Organization Management, vol. 30, 2005, 89-98.

[11] D. F. Baker, "Peer assessment in small groups: A comparison of methods" Journal of Management Education, vol. 32, 2008.,183-209.

[12] K. Cho, C. D. Schunn, and R. W. Wilson, "Validity and reliability of scaffolded peer assessment of writing from instructor and student perspectives.", Journal of Educational Psychology, vol. 98, 2006 891-901.

[13] Y. Ju Jo, K. Yon Lim, and E. Kyung Kim, “Online university students' satisfaction and persistence: Examining perceived level of presence, usefulness and ease of use as predictors in a structural models" Computers \& Education, 57, 2011, 1654-1664.

[14] P.-C. Sun, R. J. Tsai, G. Finger, Y.Y. Chen, D. Yeh, "What Drives Successful e-Learning? An Empirical Investigation of the Critical Factors Influencing Learner Satisfaction", Computers \& Education, 50, 2008, 1183-1202.

[15] W.-S. Lin and C.H. Wang, "Antecedents to continued adoptions of adopting e-learning systems in blended learning instruction: A contingency framework based on models of information system success and tasktechnology fit", Computers \& Education, 58, 2012, 88-99. 
Appendix A

Sample Peer Feedback Report- Quick Summary Page

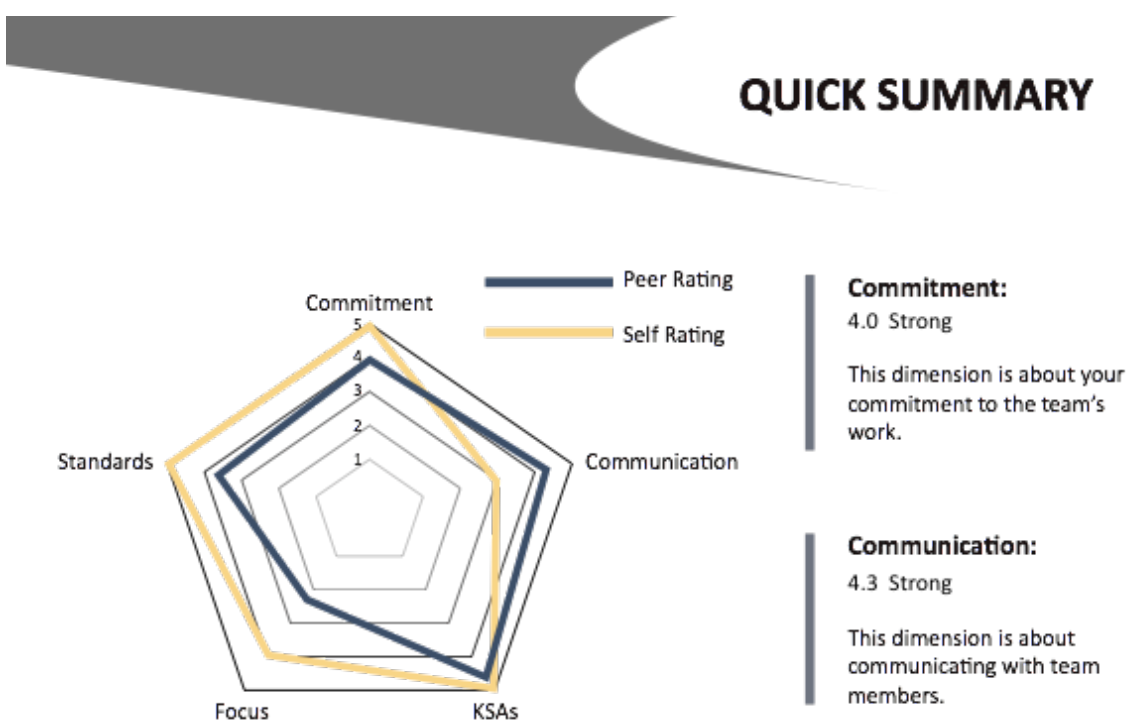

The above graph presents you with a bird's-eye view of your peer feedback results. Each corner of the pentagon represents one of the 5 teamwork competencies. Lower scores are points that fall closer to the center of the graph and higher scores are associated with points that extend toward the edge of the graph. For example, if you scored 5 on KSAs, that point would stretch to the outer edge of the graph.

When the yellow line extends past the blue line for any competency, this is a Blind Spot, meaning you rated yourself higher than your peers rated you on that competency. When the blue line extends past the yellow line, this is also a Blind Spot, but in this case your peers rated you higher than you rated yourself on that competency. Your score on each competency is displayed along the right-hand side of this page.

4.5 to $5.0=$ Outstanding

3.5 to $4.5=$ Strong

2.5 to $3.5=$ Moderate

1.5 to 2.5 = Bare Minimum

1.0 to 1.5 = Unsatisfactory

\section{KSAs:}

4.7 Outstanding

This dimension is about having a strong foundation of knowledge, skills, and abilities.

Focus:

2.3 Bare Minimum

This dimension is about keeping the team on track.

\section{Standards:}

3.7 Strong

This dimension is about emphasizing high standards. 